\title{
De Bosniak-classificatie voor niercysten: tijd voor een volgende verandering?
}

\author{
Romy E.D. Lamers · Kèren Zaccai · Ivo G. Schoots • Paul C.M.S. Verhagen
}

Published online: 27 November 2015

(C) The Author(s) 2015. This article is published with open access at Springerlink.com

Samenvatting In 1986 introduceerde Morton Bosniak een classificatie voor niercysten gebaseerd op computed tomography (CT). In de loop der jaren is de classificatie enkele keren aangepast. $\mathrm{Nu}$ zijn er vijf categorieën (I, II, IIF, III en IV). Bij categorie I en II is er geen controle of behandeling nodig, bij IIF is het advies surveillance, bij III en IV wordt behandeling geadviseerd. Interobservervariabiliteit wordt slechts in enkele studies gerapporteerd en is hoog. Recentere publicaties incorporeren een MRI-scan en contrastechografie in de Bosniak-classificatie. Beide zijn voor het vaststellen van doorbloeding gevoeliger dan een CT-scan en kunnen daarom leiden tot upgrading. Bij een Bosniak III-cyste is er in ongeveer de helft van de gevallen sprake van een maligniteit. Het betreft dan meestal cysteuze niercelcarcinomen, die klinisch milder verlopen dan solide tumoren. In onze ogen zijn er goede argumenten om bij Bosniak III-cysten $<4 \mathrm{~cm}$ surveillance toe te passen, net zoals tot nu toe gebruikelijk is bij Bosniak IIF. Het risico op tumorprogressie is bij Bosniak III-tumoren zeer klein en

\footnotetext{
dr. P.C.M.S. Verhagen $(\bowtie)$

afdeling Urologie, Erasmus Medisch Centrum, Rotterdam, Nederland

e-mail: p.verhagen@erasmusmc.nl

drs. R.E.D. Lamers

afdeling Urologie, St. Elisabeth ziekenhuis,

Tilburg, Nederland

drs. K. Zaccai

department of Urology, University College London Hospital,

Londen, Verenigd Koninkrijk

dr. I.G. Schoots

afdeling Radiologie, Erasmus Medisch Centrum,

Rotterdam, Nederland
}

overbehandeling wordt beperkt. Het wordt dan wel belangrijk om het onderscheid tussen categorie III en IV preciezer te definiëren.

Trefwoorden Bosniak-classificatie · gecompliceerde niercysten $\cdot$ niercyste $\cdot$ niercelcarcinoom

\section{The Bosniak classification for renal cysts: time for another change?}

\begin{abstract}
The Bosniak renal cyst classification was introduced in 1986. This classification was based on computed tomography (CT). In the course of years several adjustments were proposed. The current classification contains five categories: I, II, IIF, III and IV. Categorie I and II lesions are assumed benign and do not require further treatment. A IIF lesion is possibly benign and surveillance is advised. Lesions in categorie III and IV are suspect for malignancy and treatment is advised. Only few studies reported interobserver variability which was high. More recent studies incorporate MRI and CEUS in the Bosniak classification system which further impedes interpretation. MRI and CEUS are more sensitive to detect enhancement in a lesion and may upgrade a lesion compared to CT. In Bosniak III cysts the risk for malignancy is approximately $50 \%$. If malignant, histology usually shows cystic renal cell carcinoma which has been reported to follow a more favourable course compared to solid tumours. In our opinion there are good arguments to imply surveillance for Bosniak III cysts $<4 \mathrm{~cm}$, similar to the approach of IIF lesions. The risk for tumour progression is very small while overtreatment is reduced. It will be important to improve the definition of a category IV lesion.
\end{abstract}


Keywords Bosniak classification .

complex renal cystic mass - renal cyst .

renal cell carcinoma

\section{Introductie}

Morton A. Bosniak introduceerde in 1986 een classificatie voor niercysten [1]. Met de opkomst van de computed tomography (CT) werden deze cysten steeds vaker gezien als toevalsbevinding. De classificatie werd gekoppeld aan een duidelijk behandeladvies: voor categorie I en II was geen verdere bemoeienis nodig en voor laesies in categorie III en IV was het advies de cyste chirurgisch te verwijderen als er bij een patiënt geen contra-indicaties waren. In het artikel van Bosniak worden de kenmerken van de verschillende categorieën uitgebreid beschreven en geïllustreerd. Er zijn verschillende updates verschenen van De Bosniakclassificatie, waarin de kern van de classificatie intact bleef [2-9]. De toevoeging van categorie IIF in 1993 (F staat voor follow-up) beoogde het aantal interventies voor benigne afwijkingen te verminderen [3]. Terwijl het schema van vijf categorieën sindsdien identiek is gebleven, veranderde de betekenis van bepaalde radiologische kenmerken, zoals 'calcificatie' of 'mate van aankleuring'. Ondertussen veranderde ook de radiologische techniek zelf. Op een hedendaagse spiraal-CT-scan zijn details te zien die op een scan uit 1986 niet zichtbaar waren. Bovendien werden MRI en contrastechografie geïntroduceerd en ook gebruikt om de Bosniak-classificatie uit af te leiden [9-11]. We kunnen vaststellen dat er regelmatig discussie bestaat over de juiste toewijzing van een laesie aan een specifieke categorie.

Wij inventariseerden alle aanpassingen aan de Bosniakclassificatie die we vonden in de literatuur. Ook zochten we studies naar inter- en intraobservervariabiliteit. Ten slotte zochten we ook naar alle publicaties over de resultaten die werden verkregen na surveillance of operatieve behandeling van gecompliceerde niercysten.

\section{Materiaal en methode}

Met de hulp van een medisch bibliothecaris werd een literatuuronderzoek gedaan met de trefwoorden 'Bosniak', 'Bosniakclassification', 'cyst' en 'kidney tumor' en alle synoniemen in de volgende databases: Embase, Medline (OvidSP), Web of Science, Scopus, PubMed, Cinahl, and the Cochrane library. Engelstalige artikelen werden geïncludeerd vanaf 1986 tot 8 april 2015. Er werden 6282 artikelen gevonden die door drie auteurs (KZ, IS, PV) werden beoordeeld. Artikelen waarover geen consensus was, werden bediscussieerd.

\section{Resultaten}

De oorspronkelijke Bosniak-classificatie

De Bosniak-indeling onderscheidde aanvankelijk vier categorieën [1]. Categorie I omvatte alle simpele cysten (rond, egale inhoud met densiteit passend bij water, geen wandverdikking) die werden vastgesteld op een CT-scan met minimaal een blanco en een contrastserie. Categorie II-cysten waren cysten met minimale afwijkingen, zoals een dun $(<1 \mathrm{~mm})$ regulair septum of kleine calcificaties. Deze septa vertonen geen meetbare contrastopname. Hyperdense cysten (40-100 HU) die rond, scherp begrensd en homogeen waren en een doorsnee $<3 \mathrm{~cm}$ hadden en die geen aankleuring vertoonden, behoorden ook tot deze categorie. Wanneer een hyperdense cyste $>3 \mathrm{~cm}$ werd gemeten, adviseerde men aspiratie of follow-up met aanvullende CT-scans. De cysten in categorie III bevatten laesies met aankleuring in een septum of wandverdikking. Cysten met uitgebreide verdikte en nodulaire calcificaties behoorden ook tot deze groep. Alle duidelijk maligne afwijkingen met cysteuze componenten, irregulaire randen, solide partijen met aankleuring na contrasttoediening behoorden tot categorie IV [1].

\section{Aanpassingen van de Bosniak-classificatie}

Bosniak en Israel publiceerden na 1986 in verschillende tijdschriften meerdere artikelen over dit onderwerp. Zij reageerden hierin op commentaar dat naar aanleiding van de eerste publicatie was verschenen. Van elke categorie geven zij voorbeelden, maar er wordt ook gesleuteld aan de betekenis van bepaalde details. In 1991 beschrijft Bosniak bijvoorbeeld dat de wand van hyperdense cysten voor minimaal een kwart buiten de nier moeten uitsteken [2]. Dit exofytische aspect is toegevoegd om zo de gladheid van de wand en de eventuele aankleuring goed te kunnen beoordelen. Hij stelt in ditzelfde artikel dat een hyperdense cyste met een doorsnee $>3 \mathrm{~cm}$ of die intrarenaal is gelegen, chirurgische exploratie behoeft. De belangrijkste aanpassing is de toevoeging van categorie IIF in 1993 [3]. Deze categorie is toegevoegd, omdat er veel benigne afwijkingen werden gevonden in categorie III. In 2003 verschijnt een artikel van Israel en Bosniak waarin gesteld wordt dat uitgebreide calcificaties geen risicofactor zijn voor aanwezigheid van een maligniteit, in tegenstelling tot wat eerder werd aangenomen. In de herziene versie van de classificatie van 2005 wordt dit aspect aangepast. De eis dat een laesie voor een deel exofytisch moet liggen om in categorie II of IIF te komen, wordt nu niet meer genoemd.

Ten slotte is er een aanpassing van de mate van aankleuring die vereist is om van enhancement te spreken. De densiteit van weefsel wordt uitgedrukt in Hounsfield units (HU), een absolute maat voor de mate van attenuation (de mate 
waarin een röntgenstraal wordt tegengehouden of verstrooid door het weefsel). Een CT-scan wordt geijkt, zodat de dichtheid van lucht gelijk is aan - 1000 HU en die van gedestilleerd water 0 HU. HU's worden gemeten binnen een door de beoordelaar aan te geven region of interest. Enhancement of aankleuring kan worden vastgesteld als een blanco scan wordt vergeleken met een scan na contrasttoediening. Aankleuring geeft aan dat er sprake is van doorbloeding of uitscheiding. Soms is er een verbinding tussen het verzamelsysteem en een cyste, waardoor er contrast in een cyste terecht kan komen op een latefaseopname. De mate van aankleuring hangt naast de instelling van het CT-apparaat af van het uitgevoerde scanprotocol. Er kan gescand worden in de corticomedullaire (veneuze of arteriële) fase, de nefrogene (parenchymateuze) fase en de uitscheidingsfase. Soms wordt een combinatiescan gemaakt nadat er meerdere malen een bolus contrast is gegeven, zodat contrast aanwezig is in de verschillende structuren. Aanvankelijk werd een toename van $10 \mathrm{HU}$ genoemd als enhancement; latere publicaties noemen een hoger getal (toename van 15-20 HU) als criterium om van een Bosniak III- of IV-cyste te spreken [8]. Het begrip pseudo-enhancement wordt gebruikt om een minimale toename van $\mathrm{HU}$ aan te duiden (tot 10) die niet op doorbloeding is gebaseerd, maar op een CT-artefact. Een andere term die door Bosniak wordt gebruikt is perceived enhancement. Hiermee wordt bedoeld dat de septa op de contrastserie duidelijker onderscheiden kunnen worden dan op de blanco scan. Bij deze zeer dunne septa is er echter geen meetbare toename van dichtheid. Perceived enhancement duidt op capillaire doorbloeding en past bij Bosniakcategorie II of IIF.

Naast CT-beelden kan de Bosniak-classificatie ook worden afgeleid uit een MRI-scan. Door een betere contrastre- solutie worden op een MRI-scan soms extra septa, dikkere septa en aankleuring gezien, die kunnen leiden tot upgrading van de Bosniak-categorie [4, 9, 12]. In 81\% (56/69) van de cysteuze niermassa's zijn de beschrijvingen van de CT- en MRI-scan vergelijkbaar [9]. In vergelijking met CT leidt MRI in ongeveer $10 \%$ tot upgrading van Bosniak-categorie. Wanneer er gekeken wordt naar histologisch bewezen maligniteiten blijkt dat in $90 \%$ van de gevallen op grond van de MRI- en CT-scans dezelfde categorieën waren toegewezen. In 2012 verschijnt er een case report met twee voorbeelden van laesies die met CT als categorie II waren geclassificeerd, maar met MRI als categorie IV. Bij histologie blijkt er in beide gevallen sprake van een niercelcarcinoom [12].

Een andere techniek die doorbloeding kan aantonen in een complexe niercyste is echografisch onderzoek met contrast (contrast enhanced ultrasonography, CEUS). In vergelijking met CT heeft CEUS ook een hogere sensitiviteit voor het vaststellen van doorbloeding en ook voor het aantal septa $[10,11,13]$. Beeldvorming door CT en CEUS leidt in $14-26 \%$ van de gevallen tot een verschil in Bosniakclassificatie; meestal betreft het upgrading door echografie. Upgrading kan resulteren in verschillende behandelplannen $[10,11,13]$.

Bepaalde criteria die bij presentatie van de classificatie werden benoemd, zijn bij de latere versies niet expliciet herhaald. Als voorbeeld wordt een septumdikte van $>1 \mathrm{~mm}$ als criterium voor categorie III in 2005 niet meer beschreven. Verwarring kan ontstaan bij een septumdikte van $>1 \mathrm{~mm}$ en aankleuring van $<15 \mathrm{HU}$ en vice versa. Een ander voorbeeld is het exofytisch aspect als eis voor een hyperdense cyste om in categorie IIF te worden ingedeeld, dat in 2005 niet meer wordt benoemd. Tab. 1 toont een overzicht van

Tabel 1 Wijzigingen in de Bosniak-classificatie.

\begin{tabular}{ll}
\hline jaartal & wijziging \\
\hline 1986 & 1. Introductie van de Bosniak-classificatie [1] \\
& 2. Criterium voor enhancement: $>10 \mathrm{HU}[1,3]$ \\
& 3. Criterium voor septumdikte: $>1 \mathrm{~mm}$ wordt categorie III [1] \\
& Een hyperdense cyste behoort tot categorie II indien: \\
& 1. de cyste een diameter heeft <3 cm; \\
& 2. $1 / 4$ van de cystewand exofytisch gelegen is (om een goede beoordeling van de wand mogelijk te maken); \\
& 3. de cyste rond is en scherpe grenzen heeft; \\
& 4. er geen enhancement is; bij aanwezigheid van enhancement valt de cyste in categorie III [2]. \\
& Introductie van categorie IIF: \\
& - de hyperdense cyste >3 cm zonder enhancement verschuift van categorie III naar categorie IIF [3]. \\
& De follow-up van categorie IIF verandert van 3-6 maanden naar 1 jaar [3] \\
& De nodulaire calcificatie vervalt als criterium voor categorie III [6]. \\
2003 & De follow-up voor categorie IIF verandert van 6 maanden naar jaarlijks tot minstens 5 jaar [5]. \\
2005 & De Bosniak-classificatie wordt toegepast op MRI-beelden [7]. \\
2005 & Het criterium 'septumdikte >1 mm' voor categorie III vervalt [4, 7, 8]. \\
2005 & Het exofytisch aspect als eis voor een hyperdense cyste in categorie IIF vervalt [4, 7, 8]. \\
2005 & De drempelwaarde voor enhancement van > 10 HU verschuift naar 15-20 HU [8].
\end{tabular}


Tabel 2 Meest recente overzicht van de Bosniak-classificatie [7]. categorie beschrijving

I Een goedaardige cyste met een haardunne wand zonder septa, calcificaties of solide componenten. De inhoud heeft een dichtheid van water en vertoont geen enhancement.

II Een goedaardige cyste met eventueel enkele haardunne septa die perceived enhancement kunnen vertonen. Fijne calcificaties of een kort segment met een in geringe mate verdikte calcificatie kan aanwezig zijn in de wand of septa. Cysten met een gelijkmatig hoge densiteit $<3 \mathrm{~cm}$ die goed afgrensbaar zijn en geen enhancement vertonen, horen ook bij deze groep. Deze cysten hoeven niet te worden gecontroleerd.

IIF (F for Cysten met meerdere haardunne septa of minimaal follow-up) verdikte gladde wand of septa. Perceived enhancement van septa of wand kan aanwezig zijn. Dikke en nodulaire calcificatie kan aanwezig zijn in de wand of septa, maar er is geen meetbare enhancement. Deze cysten zijn meestal goed afgrensbaar. Volledig intrarenaal gelegen cysten met een hoge densiteit en een diameter $>3 \mathrm{~cm}$ behoren ook tot deze categorie. Deze cysten dienen te worden gecontroleerd.

III Deze cysten hebben verdikte irregulaire of gladde wanden of septa met meetbare enhancement. Dit zijn chirurgische laesies, alhoewel een aantal goedaardig is (bijvoorbeeld hemorragische cyste, chronisch geïnfecteerde cyste, multiloculated cystic nephroma). Een aantal is kwaadaardig zoals een cysteus niercelcarcinoom en een multiloculated cysteus niercelcarcinoom.

IV Dit zijn cysten met duidelijke kwaadaardige kenmerken die alle criteria kunnen hebben van categorie III, maar daarnaast enhancement vertonen van weefselcomponenten nabij, maar onafhankelijk van de wand of het septum. Deze afwijkingen kunnen berusten op cysteuze carcinomen en dienen chirurgisch te worden verwijderd.

wijzigingen in de criteria voor de verschillende Bosniakcategorieën. Tab. 2 toont de meest recente versie (2005) van de Bosniak-classificatie [7].

\section{De Bosniak-classificatie en het risico op maligniteit}

Categorie I-cysten hebben een verwaarloosbare kans op maligniteit. Bij categorie II-cysten die werden geopereerd was de kans op maligniteit van $13 \%$. Er is bij deze cysten wel sprake van een sterke selectiebias. Categorie II wordt immers normaal niet geopereerd en er waren ten aanzien van deze gerapporteerde gevallen blijkbaar argumenten om dat wel te doen. Beschikbare studies tonen een risico op maligniteit van $3 \%$ in categorie IIF. Ook hierbij is sprake van een bias, omdat in categorie IIF bij het grootste deel van de laesies geen histologische diagnose verkregen is. Indien uitsluitend wordt gekeken naar geopereerde patiënten (er wordt meestal geopereerd wanneer er röntgenologisch tekenen van progressie zijn) is het risico op maligniteit $34 \%$. $\mathrm{Bij}$ een radiologisch vastgestelde categorie III-laesie is het risico op maligniteit $44 \%$. Bij een categorie IV-laesie is dit risico $72 \%$. Indien we uitsluitend kijken naar de selectie van patiënten die een operatie hebben ondergaan, ligt de kans op maligniteit wat hoger, namelijk voor categorie III op 55\% en voor categorie IV op $87 \%$. Zie tab. 3 .

\section{Interobservervariabiliteit van de Bosniak-classificatie}

Wij vonden slechts drie studies waarin de interobservervariabiliteit van de Bosniak-classificatie was onderzocht $[18$, 30, 43].

Siegel et al. bestudeerden de interobservervariabiliteit bij 70 laesies die door drie radiologen werden beoordeeld. Deze studie dateert van 1997; categorie IIF wordt hier niet apart benoemd. Een consistente score van de drie beoordelaars werd gevonden in 59\% van de gevallen (41/70) [18]. De kappawaarde werd bepaald op 0,571 (redelijk). In categorie II en III werden de meeste discrepanties vastgesteld. Bertolotto et al. rapporteerden over 70 gecompliceerde cysten bij 59 patiënten. Bij deze studie werd categorie IIF wel gebruikt. Alhoewel de precieze getallen over discrepanties tussen de beoordelaars niet af te leiden zijn uit deze studie concluderen de auteurs dat hun resultaten in overeenstemming zijn met die van Siegel et al. (redelijke overeenstemming). Zij concluderen ook dat analyse van volume datasets minder discrepanties oplevert dan analyse van $5 \mathrm{~mm}$ axiale CT-beelden [43].

In het artikel van Weibl et al. werden 71 niercysten bekeken door drie beoordelaars [30]. Ook bij deze studie werd de actuele versie van de classificatie beoordeeld, inclusief categorie IIF. De resultaten tonen dat er in categorie II en IIF het meeste verschil van inzicht bestond. In categorie II werden 18 van 25 patiënten anders ingedeeld (72\%) en in categorie IIF negen van de 12 (75\%).

\section{Categorie IIF, follow-up: hoe en hoelang?}

$\mathrm{Er}$ is geen consensus over hoe de follow-up er uit zou moeten zien bij een Bosniak IIF-cyste. De gemiddelde groeisnelheid van kleine, solide niercelcarcinomen is langzaam, ongeveer $2-5 \mathrm{~mm} / \mathrm{jaar}$. Groei blijkt bij solide laesies waarvoor active surveillance werd toegepast geen onderscheidend criterium voor maligniteit, omdat ook benigne afwijkingen groei vertonen [44]. Herhaal-CT-scans worden door Bosniak geadviseerd na drie maanden, [3] door Israel en Bosniak na zes maanden [5] om vervolgens, indien de laesie onveranderd is, dit gedurende twee tot vier à vijf jaar jaarlijks te herhalen [4, 6]. Hwang et al. beschreven 201 IIFcysten die met CT-scans werden gevolgd. Bij $7 \%$ trad progressie op na een gemiddelde duur van 11 maanden (range 3-65 maanden) [33]. In tien van de 12 geopereerde laesies werd maligniteit gevonden. Smith et al. beschreven bij $13 \%$ van Bosniak IIF-cysten progressie op de CT-scan waarvan de helft maligne bleek te zijn. De mediane tijd tot progressie 
Tabel 3 Overzicht van studies die kans op maligniteit rapporteren per Bosniak-categorie.

\begin{tabular}{|c|c|c|c|c|c|c|c|c|c|c|c|c|c|}
\hline \multirow[b]{2}{*}{ auteur } & \multirow[b]{2}{*}{ jaar } & \multicolumn{3}{|c|}{ Bosniak II } & \multicolumn{3}{|c|}{ Bosniak IIF } & \multicolumn{3}{|c|}{ Bosniak III } & \multicolumn{3}{|c|}{ Bosniak IV } \\
\hline & & $\begin{array}{l}n \\
\text { totaal }\end{array}$ & $\begin{array}{l}n \\
\text { resectie }\end{array}$ & $\begin{array}{l}n \\
\text { maligne }\end{array}$ & $\begin{array}{l}n \\
\text { totaal }\end{array}$ & $\begin{array}{l}n \\
\text { resectie }\end{array}$ & $\begin{array}{l}n \\
\text { maligne }\end{array}$ & $\begin{array}{l}n \\
\text { totaal }\end{array}$ & $\begin{array}{l}n \\
\text { resectie }\end{array}$ & $\begin{array}{l}n \\
\text { maligne }\end{array}$ & $\begin{array}{l}n \\
\text { totaal }\end{array}$ & $\begin{array}{l}n \\
\text { resectie }\end{array}$ & $\begin{array}{l}n \\
\text { maligne }\end{array}$ \\
\hline Bellman $^{\mathrm{a}},[14]$ & 1995 & 5 & 5 & 0 & - & - & - & 5 & 5 & 0 & - & - & - \\
\hline Cloix $^{\mathrm{a}},[15]$ & 1996 & 7 & 7 & 1 & - & - & - & 13 & 13 & 4 & 10 & 10 & 7 \\
\hline Ooi $^{\mathrm{a}}$, [16] & 1996 & 3 & 3 & 3 & - & - & - & 4 & 3 & 3 & 2 & 2 & 2 \\
\hline Wilson ${ }^{\mathrm{a}}$, [17] & 1996 & 5 & 5 & 4 & - & - & - & 4 & 4 & 4 & 6 & 6 & 6 \\
\hline Siegel $^{\mathrm{a}},[18]$ & 1997 & 8 & 8 & 1 & - & - & - & 11 & 11 & 5 & 29 & 29 & 26 \\
\hline Balci[19] & 1999 & 36 & 18 & 0 & - & - & - & 5 & 3 & 0 & 32 & 25 & 14 \\
\hline Curry $^{\mathrm{a}},[20]$ & 2000 & 11 & 11 & 0 & - & - & - & 49 & 49 & 29 & 18 & 18 & 18 \\
\hline $\mathrm{Koga}^{\mathrm{a}},[21]$ & 2000 & 2 & 2 & 1 & - & - & - & 10 & 10 & 10 & 12 & 12 & 12 \\
\hline $\mathrm{Limb}^{\mathrm{a}}$, [22] & 2002 & 28 & 28 & 3 & - & - & - & 29 & 29 & 8 & - & - & - \\
\hline Israel [6] & 2003 & 21 & 0 & 0 & 19 & 3 & 0 & 25 & 21 & 9 & 16 & 16 & 16 \\
\hline Israel [5] & 2003 & - & - & - & 39 & 0 & - & - & - & - & - & - & - \\
\hline Harisinghani ${ }^{\mathrm{a}}$, [23] & 2003 & - & - & - & - & - & - & 28 & 28 & 17 & - & - & - \\
\hline Spaliviero $^{\mathrm{a}}$, [24] & 2005 & 9 & 9 & 2 & 4 & 4 & 1 & 12 & 12 & 6 & 21 & 21 & 19 \\
\hline Ascenti [10] & 2007 & 24 & 0 & - & 10 & 0 & - & 7 & 6 & 3 & 3 & 3 & 3 \\
\hline Clevert [11] & 2008 & 15 & 0 & - & 8 & 1 & 0 & 8 & 6 & 3 & 7 & 7 & 7 \\
\hline Song $^{\mathrm{a}},[25]$ & 2009 & 26 & 26 & 3 & 3 & 3 & 0 & 38 & 38 & 21 & 37 & 37 & 32 \\
\hline O’Malley [26] & 2009 & - & - & - & 81 & 5 & 5 & 31 & 28 & 22 & - & - & - \\
\hline Gabr [27] & 2009 & - & - & - & 50 & 0 & - & - & - & - & - & - & - \\
\hline You $^{\mathrm{a}},[28]$ & 2011 & - & - & - & - & - & - & 39 & 39 & 22 & 36 & 36 & 31 \\
\hline Pinheiro $^{\mathrm{a}}$, [29] & 2011 & - & - & - & - & - & - & 15 & 15 & 6 & 22 & 22 & 19 \\
\hline Weibl [30] & 2011 & 26 & 2 & 0 & 15 & 3 & 2 & 28 & 27 & 15 & 44 & 39 & 30 \\
\hline $\operatorname{Han}^{\mathrm{a}},[31]$ & 2012 & 9 & 9 & 0 & 18 & 18 & 3 & 39 & 39 & 21 & 32 & 32 & 29 \\
\hline Smith [32] & 2012 & - & - & - & 69 & 16 & 4 & 144 & 107 & 58 & - & - & - \\
\hline Hwang [33] & 2012 & - & - & - & 201 & 12 & 10 & - & - & - & - & - & - \\
\hline Graumann [34] & 2013 & - & - & - & 32 & 0 & - & - & - & - & - & - & - \\
\hline Goenka [35] & 2013 & - & - & - & - & - & - & 107 & 107 & 59 & - & - & - \\
\hline Reese $^{\mathrm{a}},[36]$ & 2014 & 16 & 16 & 2 & 6 & 6 & 2 & 32 & 32 & 21 & 59 & 59 & 50 \\
\hline El-Mokadem [37] & 2014 & - & - & - & 78 & 1 & 1 & 31 & 16 & 10 & 25 & 14 & 12 \\
\hline Hindman [38] & 2014 & - & - & - & 156 & 0 & 0 & - & - & - & - & - & - \\
\hline $\mathrm{Xu}[39]$ & 2014 & - & - & - & 10 & 10 & 0 & 26 & 26 & 14 & 49 & 49 & 47 \\
\hline $\mathrm{Bata}^{\mathrm{a}},[40]$ & 2014 & - & - & - & - & - & - & 19 & 19 & 16 & - & - & - \\
\hline Smith [41] & 2015 & - & - & - & 144 & 8 & 3 & 113 & 72 & 29 & 29 & 20 & 18 \\
\hline Weibl [42] & 2015 & - & - & - & 27 & - & - & 58 & 54 & 37 & - & - & - \\
\hline totaal & & 251 & 149 & 20 & 970 & 90 & 31 & 930 & 819 & 452 & 489 & 457 & 398 \\
\hline $\begin{array}{l}\text { kans maligne indien resec- } \\
\text { tie (\%) (alle studies) }\end{array}$ & & & 13 & & & 34 & & & 55 & & & 87 & \\
\hline $\begin{array}{l}\text { kans maligne t.o.v. CT- } \\
\text { beeld }(\%)\left({ }^{\text {a }} \text { studie is buiten }\right. \\
\text { beschouwing gelaten) }\end{array}$ & & & $\mathbf{0}$ & & & 3 & & & 44 & & & 72 & \\
\hline
\end{tabular}

MCRCC multilocular cystic renal cell carcinoma (RCC)

${ }^{a}$ Studies die alleen geopereerde patiënten rapporteren. Alle overige studies tonen ook het aantal patiënten met een gecompliceerde cyste op een CT-scan die niet zijn geopereerd. Het maligniteitsrisico kan worden uitgedrukt als percentage van geopereerde patiënten (selectie) of als percentage van patiënten met een vergelijkbare afwijking op de CT-scan (dan is van een aantal geen PA bekend). In categorie IIF is er een groot verschil, omdat in die categorie slechts een minderheid wordt gereseceerd. Categorie IIF werd geïntroduceerd in 1993. In de eerdere publicaties zijn deze afwijkingen terechtgekomen in zowel categorie II als III

was hier 0,5 jaar $(\mathrm{SD}=0,2-2)$. Geen van de patiënten met een IIF- of III-cyste in deze studie ontwikkelde metastasen [32]. Uit deze gegevens kunnen we afleiden dat een followup duur van vijf jaar voldoende is.

\section{Biologisch gedrag van cysteuze niercelcarcinomen}

Cysteuze niercelcarcinomen blijken een milder klinisch beloop te hebben dan solide tumoren. De vraag is wanneer men kan spreken van een cysteus niercelcarcinoom. Door centrale necrose kunnen solide tumoren op een CT-scan 
lijken op een cysteus niercelcarcinoom. Park et al. analyseerden 223 niercelcarcinomen en bepaalden microscopisch het percentage cysteuze component. Zij kwamen tot de conclusie dat een percentage van $>5 \%$ een gunstiger prognose geeft [45]. Ongeveer $15 \%$ van de heldercellige niercelcarcinomen tonen een cysteus groeipatroon. Type I papillair niercelcarcinoom kan ook grote cysten vormen. Er zijn enkele zeldzame varianten van cysteuze niercelcarcinomen opgenomen in de WHO-Classificatie van 2004 [46]. Hieronder valt ook het multilocular cystic RCC (MCRCC), een variant van het heldercellig RCC. Dit MCRCC gedraagt zich indolent, er zijn nooit metastasen beschreven [47]. Huber et al. vergeleken het beloop van 277 solide met 42 cysteuze tumoren uit hun klinisch cohort. Bij geen enkele cysteuze niertumor werden lymfekliermetastasen of metastasen op afstand vastgesteld en geen enkele patiënt overleed aan de aandoening (kankerspecifieke overleving 100\%) [48]. 32 tumoren waren heldercellig (waarvan $1 \mathrm{MCRCC}$ ) en tien papillair. Ook Reese et al. concludeerden dat de meeste cysteuze niercelcarcinomen een laag stadium en gradering hebben [36]. Donin et al. beschreven een serie van 61 patiënten die een operatie ondergingen voor diverse Bosniak-categorieën. Er waren 48 maligne laesies met een gemiddelde diameter van 3,3 cm, waarvan 21 met heldercellige histologie. Ook in deze serie ontwikkelde geen enkele patiënt een lokaal recidief of een metastase. De auteurs concludeerden dat cysteuze niercelcarcinomen niet de neiging hebben om te recidiveren of te metastaseren, ongeacht grootte, histologisch type of gradering [49].

Tab. 4 toont de oncologische uitkomsten van in totaal meer dan 1000 cysteuze niertumoren die operatief werden behandeld. Dit is een overzicht van de studies die ofwel informatie gaven over Bosniak-classificatie en follow-up, ofwel PA-uitslagen en follow-up. Uit de tabel valt af te lezen dat de prognose van deze tumoren over het algemeen zeer goed is. Slechts enkele lokale recidieven of metastasen worden gerapporteerd. De gemiddelde diameter van de tumor in dit overzicht is ongeveer $4 \mathrm{~cm}$. Het valt op dat in de serie van Ooi et al. met grotere afwijkingen (gemiddeld $10 \mathrm{~cm}$ ) het aantal patiënten met progressie veel hoger ligt $(56 \%)[16]$.

De helft van Bosniak III-cysten is niet maligne en behoeft geen operatieve behandeling. De andere helft bestaat uit cysteuze tumoren met een zeer goede prognose. Het is waarschijnlijk dat enig uitstel van behandeling hierbij veilig is. Deze argumenten pleiten ervoor om het standaardadvies bij een Bosniak III-cyste te veranderen. Deze cysten zouden dan, net als de Bosniak IIF-cyste, kunnen worden gevolgd en geopereerd indien er sprake is van progressie.

\section{Discussie}

De Bosniak-classificatie wordt veel gebruikt om complexe niercysten in te delen. Er is een grote interobservervariabiliteit. De criteria om cysten toe te schrijven aan een bepaalde categorie zijn op details gewijzigd en deze wijzigingen zijn niet bij iedere clinicus bekend. Het is wenselijk dat de criteria om tot operatieve behandeling over te gaan eenduidiger worden. De prognose van chirurgisch behandelde cysteuze niercelcarcinomen is zeer gunstig. Er is geen enkele patiënt met een IIF-laesie beschreven in de literatuur die progressie liet zien na uitgestelde behandeling. De kans op maligniteit in deze situatie is erg wisselend in publicaties: $0-100 \%$ (gemiddeld $34 \%$ in ons overzicht). Onze aanname is dat de interobservervariabiliteit om progressie op een CT-scan vast te stellen veel kleiner is dan bij het toewijzen van gecompliceerde cysten aan een bepaalde categorie. In onze ogen kan de aanpak van actief vervolgen van IIF-cysten ook veilig worden toegepast op het merendeel van de categorie III-cysten, zeker als die kleiner zijn dan $4 \mathrm{~cm}$ (dit is de gemiddelde grootte van de laesies in tab. 4). De aanzienlijke overbehandeling in deze categorie zou daarmee kunnen worden verminderd. Door deze wijziging in active surveillance van Bosniak III-laesies ontstaat er echter een behoefte aan een duidelijk criterium om het onderscheid te maken tussen categorie III en IV. Dit onderscheid is weliswaar benoemd, maar in onze ervaring kan hierover ook nogal eens discussie bestaan. Wij willen een samenwerkingsproject starten om, retrospectief, geopereerde categorie III- en IV-cysten te analyseren met het doel een objectief en reproduceerbaar criterium te vinden waarmee een hoge kans op maligniteit samenhangt. Er kan daarbij bijvoorbeeld worden gedacht aan de diameter van de afwijking of aan de dikte van nodules of een septum. In hetzelfde project kan de interobservervariabiliteit van dit criterium worden vastgesteld. Bij een categorie III-laesie lijkt dan een afwachtend beleid, conform bij een Bosniak IIF-cyste, op zijn plaats. Wij verwachten dat daarmee het aantal onnodige behandelingen zal verminderen en dat een afname van de interobservervariabiliteit zal leiden tot een consistenter therapieadvies.

\section{Conclusie}

De Bosniak-classificatie is een belangrijk instrument voor de indeling van gecompliceerde niercysten. De toepassing van dit systeem is echter niet eenvoudig. De interobservervariatie is groot. Criteria voor de indeling van cysten zijn in de loop van de tijd aangepast, hetgeen nog een extra bron van verwarring is. Enhancement van de cystewand of het septum (toename van 15-20 HU) is de belangrijkste parameter om een cyste in categorie III in te delen. Het risico op maligniteit is dan rond de $50 \%$. In aanvulling op CT kun- 
Tabel 4 Oncologisch resultaat na behandeling van cysteuze niercelcarcinomen.

\begin{tabular}{|c|c|c|c|c|c|c|c|c|c|c|c|c|c|}
\hline \multirow[t]{2}{*}{$\begin{array}{l}\text { eerste } \\
\text { auteur }\end{array}$} & \multirow[t]{2}{*}{ jaar } & \multirow[t]{2}{*}{$\begin{array}{l}\text { maligne } \\
(n)\end{array}$} & \multicolumn{4}{|c|}{$\begin{array}{l}\text { Bosniak-indeling } \\
(n)\end{array}$} & \multicolumn{3}{|l|}{ histologie } & \multirow[t]{2}{*}{$\begin{array}{l}\text { diameter } \\
(\mathrm{cm})^{\mathrm{a}}\end{array}$} & \multirow[t]{2}{*}{$\begin{array}{l}\text { FU } \\
\text { (mnd) }\end{array}$} & \multirow[t]{2}{*}{$\begin{array}{l}\text { LR of } \\
\text { meta }(n)\end{array}$} & \multirow[t]{2}{*}{ opmerkingen } \\
\hline & & & II & IIF & III & IV & clear cell & papillary & MLCRCC & & & & \\
\hline Cloix [15] & 1996 & 12 & 1 & - & 4 & 7 & 11 & 1 & - & 4,3 & 32 & 1 & \\
\hline Ooi [16] & 1996 & 9 & 1 & 3 & 3 & 2 & - & - & 2 & 10 & 180 & 5 & $\begin{array}{l}4 \text { overleden } 1-5 \text { mnd na } \\
\text { diagnose, } 3 \text { gerelateerd } \\
\text { RCC; } 1 \text { metastase }\end{array}$ \\
\hline Corica [50] & 1999 & 24 & - & - & - & - & 24 & - & - & 3,8 & 78 & 0 & \\
\hline Koga [51] & 2000 & 9 & - & - & - & - & - & - & 9 & 5,4 & 65 & 0 & \\
\hline Limb [22] & 2002 & 11 & 3 & - & 8 & - & 11 & - & - & 5,6 & 40 & 0 & \\
\hline Nassir [52] & 2002 & 12 & - & - & - & - & - & - & 12 & 3,2 & 43 & 0 & \\
\hline Han [53] & 2003 & 18 & - & - & - & - & 18 & - & - & 4,9 & 32 & 1 & 1 overleden (metastase) \\
\hline Israel [5] & 2003 & 2 & - & 2 & - & - & 1 & - & 1 & 3,9 & - & 0 & $\begin{array}{l}n=42 \text { IIF-cystes; } 3 \text { pro- } \\
\text { gressie op CT, waarvan } \\
3 \text { resectie en daarvan } 2 \\
\text { maligne }\end{array}$ \\
\hline $\begin{array}{l}\text { Spaliviero } \\
{[24]}\end{array}$ & 2005 & 32 & 2 & & 6 & 19 & 20 & 9 & - & 3,4 & 14 & 1 & $\begin{array}{l}1 \text { lokaal recidief waar- } \\
\text { voor resectie }\end{array}$ \\
\hline $\begin{array}{l}\text { Suzigan } \\
{[47]}\end{array}$ & 2006 & 45 & - & - & - & - & - & - & 45 & 4,9 & 66 & 0 & \\
\hline $\begin{array}{l}\text { Webster } \\
{[54]}\end{array}$ & 2007 & 85 & - & - & - & - & - & - & 85 & 3,9 & 60 & 0 & \\
\hline Gabr [27] & 2009 & 5 & - & 5 & - & - & 2 & 2 & - & 3 & 14 & 0 & $\begin{array}{l}n=15 \text { IIF-cystes; } 7 \text { pro- } \\
\text { gressie op CT waarvan } \\
7 \text { resectie en daarvan } 5 \\
\text { maligne; geen onder- } \\
\text { scheid tussen II en IIF }\end{array}$ \\
\hline $\begin{array}{l}\text { O’Malley } \\
{[26]}\end{array}$ & 2009 & 27 & - & 5 & 22 & - & 10 & 5 & 8 & 3,4 & 6 & 0 & \\
\hline $\begin{array}{l}\text { Cizman } \\
{[55]}\end{array}$ & 2009 & 83 & - & - & - & - & - & - & - & - & 15 & 0 & $\begin{array}{l}83 \text { biopsie bewe- } \\
\text { zen RCC, geen } \\
\text { Bosniak-verdeling }\end{array}$ \\
\hline You [28] & 2011 & 53 & - & - & 22 & 31 & 20 & & 30 & 4,2 & 43 & 2 & $\begin{array}{l}1 \text { lokaal recidief, } 1 \\
\text { metastase }\end{array}$ \\
\hline Weibl [30] & 2011 & 47 & - & 2 & 15 & 30 & - & - & - & 4,2 & 42 & 0 & \\
\hline $\begin{array}{l}\text { Pinheiro } \\
\text { [29] }\end{array}$ & 2011 & 25 & - & - & 6 & 19 & - & 2 & 22 & 4,6 & 44 & 0 & \\
\hline $\begin{array}{l}\text { Hindman } \\
{[56]}\end{array}$ & 2012 & 23 & - & 7 & 13 & 3 & - & - & 23 & 2,9 & 34 & 0 & \\
\hline $\begin{array}{l}\text { Hwang } \\
\text { [33] }\end{array}$ & 2012 & 10 & - & 10 & - & - & 6 & 3 & - & 3,2 & 23 & 0 & $\begin{array}{l}n=201 \text { IIF-cystes; } \\
14 \text { progressie op CT } \\
\text { waarvan } 12 \text { resectie en } \\
\text { daarvan } 10 \text { maligne }\end{array}$ \\
\hline Smith [32] & 2012 & 62 & - & 4 & 58 & - & 31 & 15 & 6 & - & $25-37$ & 0 & \\
\hline $\begin{array}{l}\text { Jhaveri } \\
{[57]}\end{array}$ & 2013 & 47 & - & 13 & 14 & 13 & 27 & 8 & 12 & $<4,6$ & 51 & 2 & $\begin{array}{l}\text { bij } 1 \text { metastase aanwezig } \\
\text { bij presentatie }\end{array}$ \\
\hline Zhang [58] & 2013 & 13 & - & - & - & - & - & - & - & - & $6-60$ & 0 & \\
\hline $\begin{array}{l}\text { Graumann } \\
{[34]}\end{array}$ & 2013 & 2 & - & 2 & - & - & 1 & 1 & - & 3,6 & 37 & 0 & $\begin{array}{l}n=32 \text { IIF-cystes; } 5 \text { pro- } \\
\text { gressie op CT waarvan } \\
3 \text { resectie en daarvan } 2 \\
\text { maligne }\end{array}$ \\
\hline Chen [59] & 2014 & 67 & - & - & - & - & - & - & - & - & 42 & 0 & \\
\hline Donin [49] & 2014 & 48 & 1 & 3 & 53 & 4 & 21 & 10 & - & 3,3 & 48 & 0 & $\begin{array}{l}\text { Bosniak-verdeling is } \\
\text { inclusief benigne cysten }\end{array}$ \\
\hline $\begin{array}{l}\text { El-Moka- } \\
\text { dem [37] }\end{array}$ & 2014 & 29 & - & 7 & 10 & 12 & 18 & 9 & - & 4,5 & 28 & 0 & \\
\hline Huber [48] & 2014 & 42 & - & 1 & 21 & 20 & 32 & 10 & - & 3 & 20 & 0 & \\
\hline
\end{tabular}


Tabel 4 (vervolg)

\begin{tabular}{|c|c|c|c|c|c|c|c|c|c|c|c|c|c|}
\hline \multirow[t]{2}{*}{$\begin{array}{l}\text { eerste } \\
\text { auteur }\end{array}$} & \multirow[t]{2}{*}{ jaar } & \multirow[t]{2}{*}{$\begin{array}{l}\text { maligne } \\
(n)\end{array}$} & \multicolumn{4}{|c|}{$\begin{array}{l}\text { Bosniak-indeling } \\
(n)\end{array}$} & \multicolumn{3}{|l|}{ histologie } & \multirow[t]{2}{*}{$\begin{array}{l}\text { diameter } \\
(\mathrm{cm})^{\mathrm{a}}\end{array}$} & \multirow[t]{2}{*}{$\begin{array}{l}\text { FU } \\
(\mathrm{mnd})\end{array}$} & \multirow[t]{2}{*}{$\begin{array}{l}\text { LR of } \\
\text { meta }(n)\end{array}$} & \multirow[t]{2}{*}{ opmerkingen } \\
\hline & & & II & IIF & III & IV & clear cell & papillary & MLCRCC & & & & \\
\hline$\overline{\text { Reese [36] }}$ & 2014 & 89 & 2 & 2 & 21 & 50 & 56 & 22 & - & $\begin{array}{l}14<4 \mathrm{~cm} ; \\
23>4 \mathrm{~cm}\end{array}$ & 43 & 1 & $\begin{array}{l}1 \text { lokaal recidief na } 21 \\
\text { maanden }\end{array}$ \\
\hline Weibl [42] & 2015 & 45 & - & 8 & 37 & - & 31 & 14 & - & 3,7 & 36 & 1 & 1 lokaal recidief \\
\hline Smith [41] & 2015 & 50 & - & 2 & 29 & 18 & 27 & 12 & 5 & - & 29 & 2 & $\begin{array}{l}1 \text { lokaal recidief waar- } \\
\text { voor ablatie en daarna } \\
\text { metastase, } 1 \text { overleden } \\
\text { na metastase en lokaal } \\
\text { recidief (cytoreductieve } \\
\text { nefrectomie) }\end{array}$ \\
\hline
\end{tabular}

$L R$ lokaal recidief, meta metastase

${ }^{a}$ Mediaan of gemiddelde afhankelijk van gerapporteerde waarde

nen MRI en CEUS gebruikt worden voor de beoordeling van een gecompliceerde niercyste. De Bosniak-classificatie die hiermee wordt vastgesteld, is gemiddeld wat hoger dan die met CT wordt gevonden. Cysteuze niercelcarcinomen hebben een milder klinisch beloop dan solide tumoren. Er zijn in onze ogen goede argumenten om het oorspronkelijke advies bij categorie III, om de laesie operatief te verwijderen, aan te passen. Een active surveillance, zoals toegepast bij categorie IIF is waarschijnlijk veilig, zeker bij laesies $<4 \mathrm{~cm}$.

Open Access This article is distributed under the terms of the Creative Commons Attribution 4.0 International License (http://creativecommons.org/licenses/by/4.0/), which permits unrestricted use, distribution, and reproduction in any medium, provided you give appropriate credit to the original author(s) and the source, provide a link to the Creative Commons license, and indicate if changes were made.

\section{Literatuur}

1. Bosniak MA. The current radiological approach to renal cysts. Radiology. 1986;158(1):1-10.

2. Bosniak MA. Difficulties in classifying cystic lesions of the kidney. Urol Radiol. 1991;13(2):91-3.

3. Bosniak MA. Problems in the radiologic diagnosis of renal parenchymal tumors. Urol Clin North Am. 1993;20(2):217-30.

4. Bosniak MA. The Bosniak renal cyst classification: 25 years later. Radiology. 2012;262(3):781-5.

5. Israel GM, Bosniak MA. Follow-up CT of moderately complex cystic lesions of the kidney (Bosniak category IIF). AJR Am J Roentgenol. 2003;181(3):627-33.

6. Israel GM, Bosniak MA. Calcification in cystic renal masses: is it important in diagnosis? Radiology. 2003;226(1):47-52.

7. Israel GM, Bosniak MA. An update of the Bosniak renal cyst classification system. Urology. 2005;66(3):484-8.

8. Israel GM, Bosniak MA. How I do it: evaluating renal masses. Radiology. 2005;236(2):441-50.

9. Israel GM, Hindman N, Bosniak MA. Evaluation of cystic renal masses: comparison of CT and MR imaging by using the Bosniak classification system. Radiology. 2004;231(2):365-71.

10. Ascenti G, Mazziotti S, Zimbaro G, et al. Complex cystic renal masses: characterization with contrast-enhanced US. Radiology. 2007;243(1):158-65.
11. Clevert DA, Minaifar N, Weckbach S, et al. Multislice computed tomography versus contrast-enhanced ultrasound in evaluation of complex cystic renal masses using the Bosniak classification system. Clin Hemorheol Microcirc. 2008;39(1-4):171-8.

12. Kim WB, Lee SW, Doo SW, et al. Category migration of renal cystic masses with use of gadolinium-enhanced magnetic resonance imaging. Korean J Urol. 2012;53(8):573-6.

13. Park BK, Kim B, Kim SH, et al. Assessment of cystic renal masses based on Bosniak classification: comparison of CT and contrastenhanced US. Eur J Radiol. 2007;61(2):310-4.

14. Bellman GC, Yamaguchi R, Kaswick J. Laparoscopic evaluation of indeterminate renal cysts. Urology. 1995;45(6):1066-70.

15. Cloix P, Martin X, Pangaud C, et al. Surgical management of complex renal cysts: a series of 32 cases. J Urol. 1996;156(1):28-30.

16. Ooi GC, Sagar G, Lynch D, et al. Cystic renal cell carcinoma: radiological features and clinico-pathological correlation. Clin Radiol. 1996;51(11):791-6.

17. Wilson TE, Doelle EA, Cohan RH, et al. Cystic renal masses: a reevaluation of the usefulness of the Bosniak classification system. Acad Radiol. 1996;3(7):564-70.

18. Siegel CL, McFarland EG, Brink JA, et al. CT of cystic renal masses: analysis of diagnostic performance and interobserver variation. AJR Am J Roentgenol. 1997;169(3):813-8.

19. Balci NC, Semelka RC, Patt RH, et al. Complex renal cysts: findings on MR imaging. Am J Roentgenol. 1999;172(6):1495-500.

20. Curry NS, Cochran ST, Bissada NK. Cystic renal masses: accurate Bosniak classification requires adequate renal CT. AJR Am J Roentgenol. 2000;175(2):339-42.

21. Koga S, Nishikido M, Inuzuka S, et al. An evaluation of Bosniak's radiological classification of cystic renal masses. BJU Int. 2000;86(6):607-9.

22. Limb J, Santiago L, Kaswick J, Bellman GC. Laparoscopic evaluation of indeterminate renal cysts: long-term follow-up. J Endourol. 2002;16(2):79-82.

23. Harisinghani MG, Maher MM, Gervais DA, et al. Incidence of malignancy in complex cystic renal masses (Bosniak category III): should imaging-guided biopsy precede surgery? Am J Roentgenol. 2003;180(3):755-8.

24. Spaliviero M, Herts BR, Magi-Galluzzi C, et al. Laparoscopic partial nephrectomy for cystic masses. J Urol. 2005;174(2):614-9.

25. Song C, Min GE, Song K, et al. Differential diagnosis of complex cystic renal mass using multiphase computerized tomography. J Urol. 2009;181(6):2446-50.

26. O'Malley RL, Godoy G, Hecht EM, et al. Bosniak category IIF designation and surgery for complex renal cysts. J Urol. 2009; 182(3):1091-5. 
27. Gabr AH, Gdor Y, Roberts WW, Wolf JS Jr. Radiographic surveillance of minimally and moderately complex renal cysts. BJU Int. 2009;103(8):1116-9.

28. You D, Shim M, Jeong IG, et al. Multilocular cystic renal cell carcinoma: clinicopathological features and preoperative prediction using multiphase computed tomography. BJU Int. 2011;108(9):1444-9.

29. Pinheiro T, Sepulveda F, Natalin RH, et al. Is it safe and effective to treat complex renal cysts by the laparoscopic approach? J Endourol. 2011;25(3):471-6.

30. Weibl P, Klatte T, Kollarik B, et al. Interpersonal variability and present diagnostic dilemmas in Bosniak classification system. Scand J Urol Nephrol. 2011;45(4):239-44.

31. Han HH, Choi KH, Oh YT, et al. Differential diagnosis of complex renal cysts based on lesion size along with the Bosniak renal cyst classification. Yonsei Med J. 2012;53(4):729-33.

32. Smith AD, Remer EM, Cox KL, et al. Bosniak category IIF and III cystic renal lesions: outcomes and associations. Radiology. 2012;262(1):152-60.

33. Hwang JH, Lee CK, Yu HS, et al. Clinical outcomes of Bosniak category IIF complex renal cysts in Korean patients. Korean J Urol. 2012;53(6):386-90.

34. Graumann O, Osther SS, Karstoft J, Horlyck A, Osther PJ. Evaluation of Bosniak category IIF complex renal cysts. Insights Imaging. 2013;4(4):471-80.

35. Goenka AH, Remer EM, Smith AD, et al. Development of a clinical prediction model for assessment of malignancy risk in bosniak III renal lesions. Urology. 2013;82(3):630-5.

36. Reese AC, Johnson PT, Gorin MA, et al. Pathological characteristics and radiographic correlates of complex renal cysts. Urol Oncol. 2014;32(7):1010-16.

37. El-Mokadem I, Budak M, Pillai S, et al. Progression, interobserver agreement, and malignancy rate in complex renal cysts ( $\geq$ Bosniak category IIF). Urol Oncol. 2014;32(1):24 e1-7.

38. Hindman NM, Hecht EM, Bosniak MA. Follow-up for Bosniak category $2 \mathrm{~F}$ cystic renal lesions. Radiology. 2014;272(3):757-66.

39. Xu Y, Zhang S, Wei X, Pan Y, Hao J. Contrast enhanced ultrasonography prediction of cystic renal mass in comparison to histopathology. Clin Hemorheol Microcirc. 2014;58(3):429-38.

40. Bata P, Tarnoki AD, Tarnoki DL, et al. Bosniak category III cysts are more likely to be malignant than we expected in the era of multidetector computed tomography technology. J Res Med Sci. 2014;19(7):634-8.

41. Smith AD, Allen BC, Sanyal R, et al. Outcomes and complications related to the management of Bosniak cystic renal lesions. AJR Am J Roentgenol. 2015;204(5):W550-6.

42. Weibl P, Hora M, Kollarik B, et al. Management, pathology and outcomes of Bosniak category IIF and III cystic renal lesions. World J Urol. 2015;33(3):295-300.

43. Bertolotto M, Zappetti R, Cavallaro M, et al. Characterization of atypical cystic renal masses with MDCT: comparison of 5-mm axial images and thin multiplanar reconstructed images. AJR Am J Roentgenol. 2010;195(3):693-700.

44. Mason RJ, Abdolell M, Trottier G, et al. Growth kinetics of renal masses: analysis of a prospective cohort of patients undergoing active surveillance. Eur Urol. 2011;59(5):863-7.
45. Park HS, Lee K, Moon KC. Determination of the cutoff value of the proportion of cystic change for prognostic stratification of clear cell renal cell carcinoma. J Urol. 2011;186(2):423-9.

46. Lopez-Beltran A, Scarpelli M, Montironi R, Kirkali Z. 2004 WHO classification of the renal tumors of the adults. Eur Urol. 2006;49(5):798-805.

47. Suzigan S, Lopez-Beltran A, Montironi R, et al. Multilocular cystic renal cell carcinoma: a report of 45 cases of a kidney tumor of low malignant potential. Am J Clin Pathol. 2006;125(2):217-22.

48. Huber J, Winkler A, Jakobi H, et al. Preoperative decision making for renal cell carcinoma: cystic morphology in cross-sectional imaging might predict lower malignant potential. Urol Oncol. 2014;32(1):37 e1-6.

49. Donin NM, Mohan S, Pham H, et al. Clinicopathologic outcomes of cystic renal cell carcinoma. Clin Genitourin Cancer. 2015;13(1):67-70.

50. Corica FA, Iczkowski KA, Cheng L, et al. Cystic renal cell carcinoma is cured by resection: a study of 24 cases with long-term followup. J Urol. 1999;161(2):408-11.

51. Koga S, Nishikido M, Hayashi T, Matsuya F, Saito Y, Kanetake H. Outcome of surgery in cystic renal cell carcinoma. Urology. 2000;56(1):67-70.

52. Nassir A, Jollimore J, Gupta R, et al. Multilocular cystic renal cell carcinoma: a series of 12 cases and review of the literature. Urology. 2002;60(3):421-7.

53. Han KR, Janzen NK, McWhorter VC, et al. Cystic renal cell carcinoma: biology and clinical behavior. Urol Oncol. 2004;22(5):410-4.

54. Webster WS, Thompson RH, Cheville JC, et al. Surgical resection provides excellent outcomes for patients with cystic clear cell renal cell carcinoma. Urology. 2007;70(5):900-4. (discussion 4).

55. Cizman Z, Rodriguez R, Hong K, Georgiades CS. Percutaneous cryoablation for renal cell carcinoma: efficacy and 3-year survival outcomes. Cardiovasc Intervent Radiol. 2009;32:306.

56. Hindman NM, Bosniak MA, Rosenkrantz AB, et al. Multilocular cystic renal cell carcinoma: comparison of imaging and pathologic findings. AJR Am J Roentgenol. 2012;198(1):W20-6.

57. Jhaveri K, Gupta P, Elmi A, et al. Cystic renal cell carcinomas: do they grow, metastasize, or recur? AJR Am J Roentgenol. 2013;201(2):W292-6.

58. Zhang J, Liu B, Song N, et al. Diagnosis and treatment of cystic renal cell carcinoma. World J Surg Oncol. 2013;11:158.

59. Chen S, Jin B, Xu L, et al. Cystic renal cell carcinoma: a report of 67 cases including 4 cases with concurrent renal cell carcinoma. BMC Urol. 2014;14:87.

drs. Romy E.D. Lamers, anios.

drs. Kèren Zaccai, anios.

dr. Ivo G. Schoots, radioloog.

dr. Paul C.M.S. Verhagen, uroloog. 


\section{Hier staat een advertentie.}

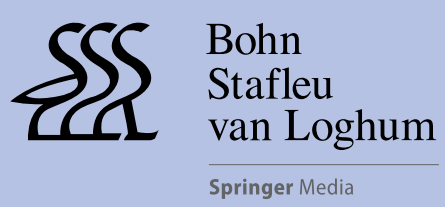

Houten 2015 


\section{Hier staat een advertentie.}

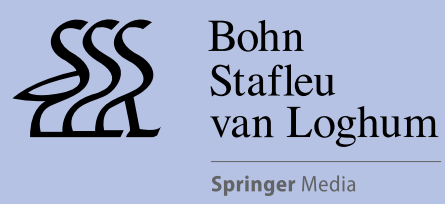

Houten 2015 


\section{Hier staat een advertentie.}

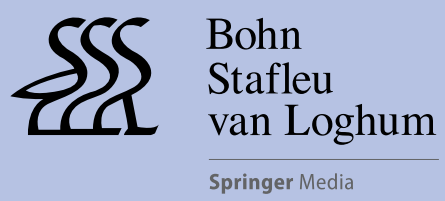

Houten 2015 
Hier staat een advertentie.

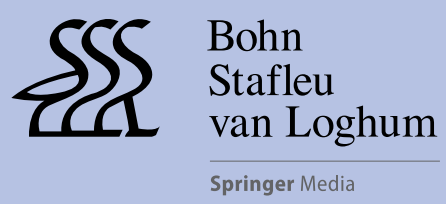

Houten 2015 